\title{
Extraction of Polysaccharide from Spirulina and Evaluation of Its Activities
}

\author{
Bingyue Wang, ${ }^{1}$ Qian Liu, ${ }^{2}$ Yinghong Huang, ${ }^{3}$ Yueling Yuan, ${ }^{1}$ Qianqian $\mathrm{Ma}^{1}$ \\ Manling Du, ${ }^{1}$ Tiange Cai $\mathbb{D}^{4},{ }^{4}$ and Yu Cai ${ }^{1,5}$ \\ ${ }^{1}$ College of Pharmacy, Jinan University, Guangzhou 510632, China \\ ${ }^{2}$ Guangzhou Jiayuan Pharmaceutical Technology Co., Ltd., Guangzhou 510632, China \\ ${ }^{3}$ Guangzhou Guoyu Pharmaceutical Technology Co., Ltd., Guangzhou 510632, China \\ ${ }^{4}$ College of Life Sciences, Liaoning University, Shenyang 110000, China \\ ${ }^{5}$ Cancer Institute of Jinan University, Guangzhou 510632, China
}

Correspondence should be addressed to Tiange Cai; caitiange@163.com and Yu Cai; caiyu8615@163.com

Received 2 September 2017; Revised 5 December 2017; Accepted 17 December 2017; Published 11 April 2018

Academic Editor: Ken Yasukawa

Copyright (c) 2018 Bingyue Wang et al. This is an open access article distributed under the Creative Commons Attribution License, which permits unrestricted use, distribution, and reproduction in any medium, provided the original work is properly cited.

\begin{abstract}
Background. Polysaccharide of Spirulina platensis (PSP) is a kind of water-soluble polysaccharide extracted from Spirulina platensis. It has been proved to have antitumor, antioxidation, antiaging, and antivirus properties. And it has a promising prospect for wide application. Objective. This study aims to identify an extraction process for high-purity polysaccharide in Spirulina (PSP) through a series of optimization methods and then evaluates its initial antiaging activities. Methods. Four kinds of extraction methods-hotwater extraction, alkali extraction, ultrasonic-assisted extraction, and freeze-thaw extraction-were compared to find the optimal one, which was further optimized by response surface methodology. PSP was obtained after the crude PSP was deproteinized and depigmented. The antiaging effects of PSP were preliminarily evaluated through in vitro cell experiments. Results. The alkali extraction method was determined as the optimal method, with the optimized extraction process consisting of a solid-liquid ratio of $1: 50$, a $\mathrm{pH}$ value of 10.25 , a temperature of $89.24^{\circ} \mathrm{C}$, and a time of $9.99 \mathrm{~h}$. The final PSP contained $71.65 \%$ of polysaccharide and $8.54 \%$ of protein. At a concentration of $50 \mu \mathrm{g} / \mathrm{mL}$, PSP exerted a significant promoting effect on the proliferation and traumatic fusion of human immortalized epidermal cells HaCaT. Conclusion. An extraction method for high-purity PSP with a high extraction rate was established, and in vitro results suggest antioxidation and antiaging activities.
\end{abstract}

\section{Introduction}

Spirulina is a genus of edible and nutritious prokaryotes, which contains up to $60 \%-70 \%$ protein, $6 \%-12 \%$ polysaccharide, and a variety of vitamins, fatty acids, and minerals [1]. Moreover, Spirulina exhibits biological activities in the human body and plays a unique role in the fields of medicine and healthcare [2-4]. Polysaccharide in Spirulina (PSP) has been reported to have antitumor $[5,6]$, antioxidation $[7,8]$, antiaging [9], immune regulation [10], and antivirus activities $[11,12]$. In addition, PSP has effects on anti-inflammatory [13], antiradiation, antifatigue, and antimutation activities [14-16]. The activities of polysaccharide vary with the structure and existing form. Thus, the structure needs to be kept intact during the extraction process.. A wall-breaking method, such as ultrasound and microwave, is required before extracting plant polysaccharide $[17,18]$. Common extraction methods include water extraction [6, 19], alcohol precipitation, acidbase extraction, ultrasonic extraction [20], freeze-thaw, and enzymatic hydrolysis [21].

\section{Materials}

2.1. Main Experimental Equipment. The experimental setup included High Performance Liquid Chromatography (Agilent 1260, RI-II), a $\mathrm{pH}$ meter ( $\mathrm{pH} 10 / 100$, Shanghai Di Yim Instrument Limited Company), an analytical balance (Q/SGYM1008, Austrian House Equipment Co., Ltd.), a 
decolorization shaker (TS-1000, Haimen Bell Instrument Manufacturing Co., Ltd.), and an inverted fluorescence microscope (TS100, Nikon Company).

2.2. Main Experimental Materials and Reagents. The reagents included Spirulina powder (20150116, Yunnan Green A Biological Engineering Co., Ltd.), papain (20150225, Nanning Pangbo Biological Engineering Co., Ltd.), Dulbecco's modified Eagle's medium (DMEM; Gibco Company), trypsin solution (Gibco Company), and Australian fetal bovine serum (Corning Corporation).

\section{Screening and Optimization of PSP Extraction Methods}

3.1. Hot-Water Extraction Method [6, 19, 22]. Spirulina powder $(40 \mathrm{~g})$ was added to $1.6 \mathrm{~kg}$ of water. The mixture was stirred vigorously in a water bath $\left(80^{\circ} \mathrm{C}\right)$ for $8 \mathrm{~h}$, followed by centrifugation $(4300 \mathrm{rpm}, 20 \mathrm{~min})$. The supernatant was concentrated to $1 / 5$ of the original volume. Subsequently, five times the volume of $95 \%$ ethanol was added to the concentrated solution. The ethanol mixture was placed in a freezer overnight, followed by centrifuging (4300 rpm) for $10 \mathrm{~min}$. The precipitate was washed by acetone, suctionfiltered, and then dried. The polysaccharide extraction rate (polysaccharide mass/Spirulina powder dry weight $\times 100 \%$ ) and protein content (protein mass/crude polysaccharide mass $\times 100 \%)$ were determined.

3.2. Lye Extraction Method [23]. Spirulina powder ( $40 \mathrm{~g}$ ) was added to $1.6 \mathrm{~kg}$ of water, and the $\mathrm{pH}$ was adjusted to 10.0 by adding $1 \mathrm{~mol} / \mathrm{L} \mathrm{NaOH}$. The succeeding experimental steps were the same as those in Section 3.1.

3.3. Ultrasound-Assisted Extraction Method [20]. Spirulina powder $(40 \mathrm{~g})$ was added to $1.6 \mathrm{~kg}$ of water, and the mixture was subjected to ultrasonication for $50 \mathrm{~min}\left(50^{\circ} \mathrm{C}, 320 \mathrm{~W}\right)$. The remaining experimental steps were the same as those in Section 3.1.

3.4. Freeze-Thaw Method. Spirulina powder ( $40 \mathrm{~g})$ was added to $1.6 \mathrm{~kg}$ of water. Then, the mixture was frozen at $4^{\circ} \mathrm{C}$ for $1 \mathrm{~h}$ and hot-melted at $30^{\circ} \mathrm{C}$ for $1 \mathrm{~h}$. These steps were repeated three times, and the subsequent experimental steps were the same as those in Section 3.1.

3.5. Single-Factor Inspection of Lye Extraction Method and Response Surface Methodology [23]. The effects of the solidliquid ratio $(1: 10,1: 20,1: 30,1: 40$, and $1: 50), \mathrm{pH}(7.0,8.0$, 9.0, 10.0, and 11.0$)$, temperature $\left(50^{\circ} \mathrm{C}, 60^{\circ} \mathrm{C}, 70^{\circ} \mathrm{C}, 80^{\circ} \mathrm{C}\right.$, and $\left.90^{\circ} \mathrm{C}\right)$, and time $(6,7,8,9$, and $10 \mathrm{~h})$ on the extraction rate were studied. Then, several levels with a considerable effect on the polysaccharide extraction rate were selected in accordance with the single-factor test. Response surface design was performed, with the polysaccharide extraction rate and protein content as the response values (Table 1). Extract the PSP according to the experimental schemes provided by Design-Expert ${ }^{\circledR}$ Version 8.0 software. Then get the optimal
TABLE 1: Factors and levels for RSD.

\begin{tabular}{lccc}
\hline Factors & \multicolumn{3}{c}{ Levels } \\
& -1 & 0 & 1 \\
\hline Solid-liquid ratio $\left(X_{1}\right)$ & 30 & 40 & 50 \\
$\mathrm{pH}\left(X_{2}\right)$ & 8 & 9 & 10 \\
Temperature $\left(X_{3}\right)$ & 70 & 80 & 90 \\
Time $\left(X_{4}\right)$ & 8 & 9 & 10 \\
\hline
\end{tabular}

prediction prescription by analyzing the results in DesignExpert. Subsequently, the optimal extraction prescription was verified. All experiments were repeated three times.

3.6. Verification of the Optimal Extraction Process. The optimal extraction process (solid-liquid ratio $=1: 50, \mathrm{pH}=$ 10.25 , temperature $=90^{\circ} \mathrm{C}$, and time $=10 \mathrm{~h}$ ) based on the aforementioned response surface design was repeated three times and then the extraction rate was determined.

3.7. Deproteinization and Decolorization. The crude polysaccharide was dissolved in distilled water, adjusted to $\mathrm{pH} 7.0$ by hydrochloric acid, and then incubated at $50^{\circ} \mathrm{C}$ for $2.5 \mathrm{~h}$ after adding $3 \%$ papain. Subsequently, the mixture was boiled to inactivate the enzyme and then kept at $4^{\circ} \mathrm{C}$ overnight after $5 \%$ trichloroacetic acid (TCA) was added. The mixture was centrifuged to get the supernatant, which precipitated overnight again with 5\% TCA. The fully deproteinized polysaccharide solution maintained at $55^{\circ} \mathrm{C}$ was adjusted to $\mathrm{pH} 8.0$ by concentrated ammonia, following addition of $\mathrm{H}_{2} \mathrm{O}_{2}$ solution (30\%) which kept a 5\% final concentration for $2 \mathrm{~h}$. After that, five times the volume of $95 \%$ ethanol was added and stored at $4^{\circ} \mathrm{C}$ overnight to precipitate. The precipitate was dissolved in distilled water and the precipitation process was repeated with $95 \%$ ethanol three times. The final precipitate was washed consecutively with anhydrous ethanol, acetone, and ether and then dried. And the protein content and polysaccharide extraction rate were calculated.

3.8. Determination of Polysaccharide Components. Crude polysaccharides $(200 \mathrm{mg})$ after deproteinization and depigmentation were dissolved by $2 \mathrm{ml}$ of $72 \%$ (w/w) sulfuric acid, followed by water bath at $30^{\circ} \mathrm{C}$ for $1 \mathrm{~h}$. Then the solution was diluted by ultrapure water to a final sulfuric acid at $4 \%(\mathrm{w} / \mathrm{w})$, subjected to hydrolysis at $121^{\circ} \mathrm{C}$ for $1 \mathrm{~h}$, and filtered by $0.45 \mathrm{um}$ membrane. The filtrate was neutralized with $\mathrm{BaCO}_{3}$ and then left at $4^{\circ} \mathrm{C}$ for 24 hours and was then filtered again to remove the precipitate; then, the final hydrolyzate was obtained.

High Performance Liquid Chromatography (Agilent 1260, RI) conditions are as follows: column ZORBAX $\mathrm{NH}_{2}$ $(4.6 \times 250 \mathrm{~mm}, 5 \mathrm{um})$, mobile phase $(75 \%$ acetonitrile in water), column temperature $\left(35^{\circ} \mathrm{C}\right)$, injection volume (10 ul), and flow rate $(0.8 \mathrm{ml} / \mathrm{min})$.

\section{Effect of PSP on HaCaT Cell Wound Healing}

HaCaT cells were cultured in RPMI-1640 medium supplemented with $10 \%$ FBS and 1\% penicillin-streptomycin under 


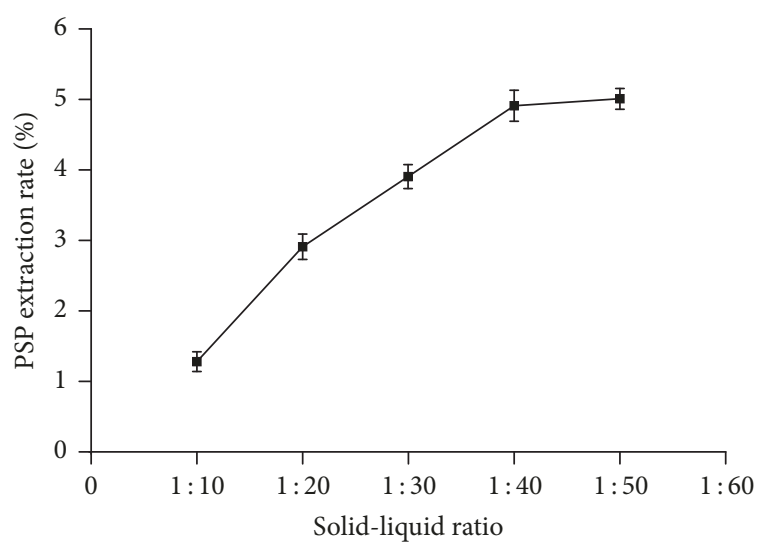

(a)

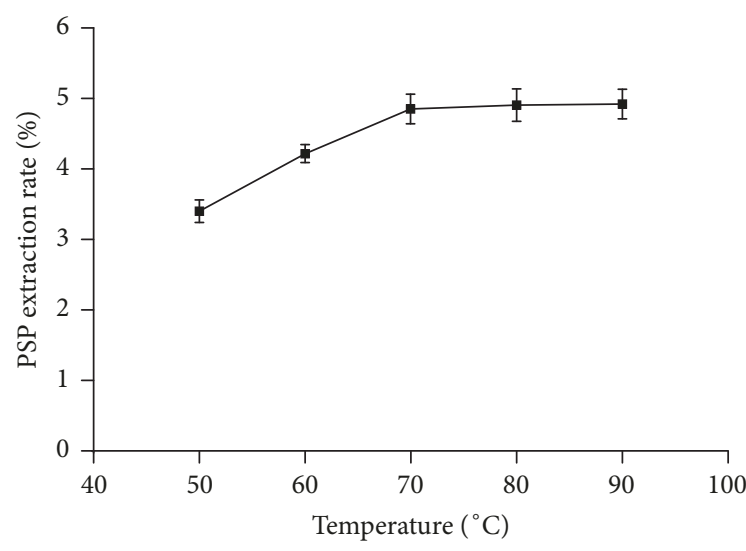

(c)

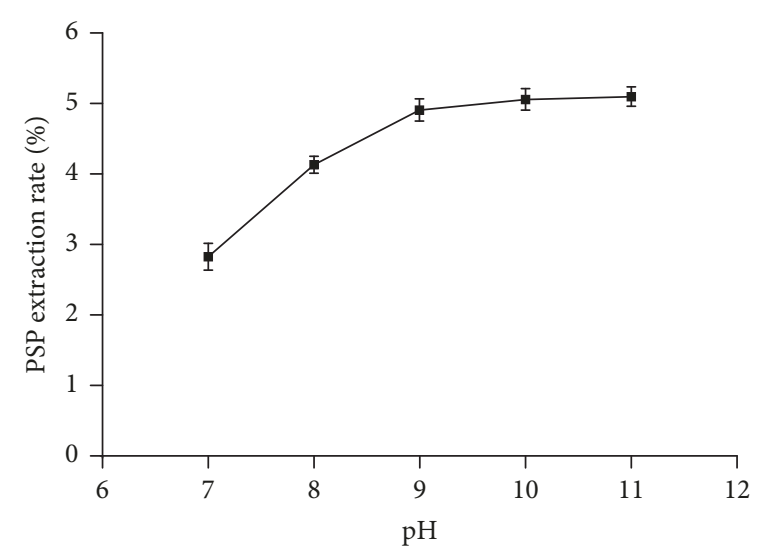

(b)

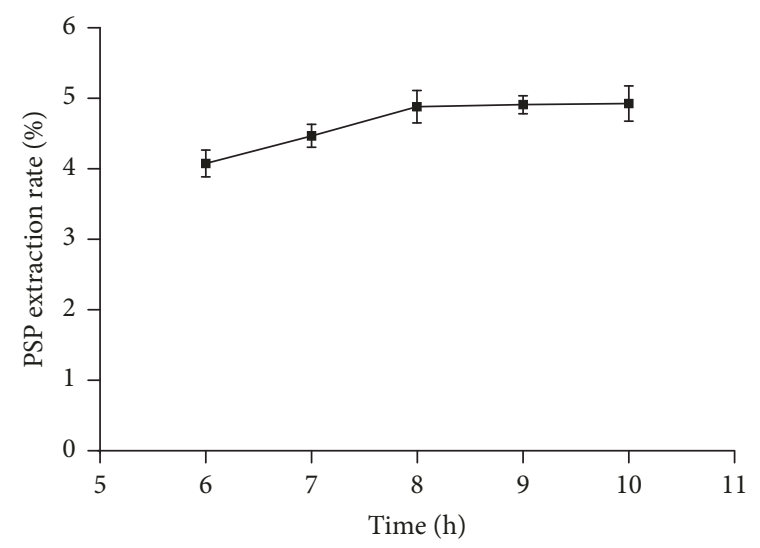

(d)

FIGURE 1: Effects of different ratios of liquid to material (a), $\mathrm{pH}(\mathrm{b})$, temperature (c), and time (d) on the extraction rate of PSP.

a humidified, $5 \% \mathrm{CO}_{2}$ atmosphere at $37^{\circ} \mathrm{C}$. Cells were used for experiments at $80 \%$ confluency. Cells were incubated at a cell density of $5 \times 10^{5}$ cells/well overnight in six-well plates (Corning, NY, USA), which were marked with equidistant horizontal lines through marker strokes. When the cells were $100 \%$ fused, the medium was then removed and longitudinal scratches were made on the cell monolayer using the tip of a $10 \mu \mathrm{L}$ pipette according to the mark line on the back of the board. This procedure produced the cell wound model. After scratching, the cells were washed three times with PBS, and the exfoliated cells were washed down. These cells were randomly divided into three groups: the normal group (only culture medium was added), the experimental group (the best concentration of proliferation in the cell proliferation experiment), and the positive control group $(20 \mathrm{ng} / \mathrm{mL}$ growth factor bFGF). $2 \mathrm{~mL}$ of fresh medium in different treatment was added at the indicated time, and the distance between scratches was observed under an inverted microscope.

\section{Results}

5.1. Selection of Different PSP Extraction Methods. Aliquot dry Spirulina powder was subjected to the hot-water extraction method (Method 1), alkaline extraction (Method 2),
TABLE 2: Extraction rate, polysaccharide content, and protein content of crude PSP obtained by different extraction methods $(n=$ $3)$.

\begin{tabular}{lccc}
\hline Method & $\begin{array}{c}\text { Extraction } \\
\text { rate }(\%)\end{array}$ & $\begin{array}{c}\text { Polysaccharide } \\
\text { content }(\%)\end{array}$ & $\begin{array}{c}\text { Protein } \\
\text { content }(\%)\end{array}$ \\
\hline 1 & $3.52 \pm 0.04$ & $9.53 \pm 0.10$ & $41.91 \pm 0.77$ \\
2 & $4.37 \pm 0.05$ & $10.8 \pm 0.13$ & $34.8 \pm 0.53$ \\
3 & $3.88 \pm 0.05$ & $8.97 \pm 0.08$ & $40.17 \pm 0.44$ \\
4 & $3.97 \pm 0.07$ & $10.16 \pm 0.16$ & $47.7 \pm 0.78$ \\
\hline
\end{tabular}

ultrasonic-assisted extraction (Method 3), or freeze-thaw method (Method 4). A light blue-green powder was eventually obtained. The results are presented in Table 2.

5.2. Single-Factor Test. The material-to-liquid ratio, $\mathrm{pH}$, temperature, and time were considered as the abscissas, while the polysaccharide extraction rate and protein content were considered as the ordinates. Trend lines were drawn based on the different conditions. The results are presented in Figures 1 and 2. As shown, the effects of different factors on the polysaccharide extraction rate follow the order of materialto-liquid ratio $>\mathrm{pH}>$ water bath temperature $>$ extraction 


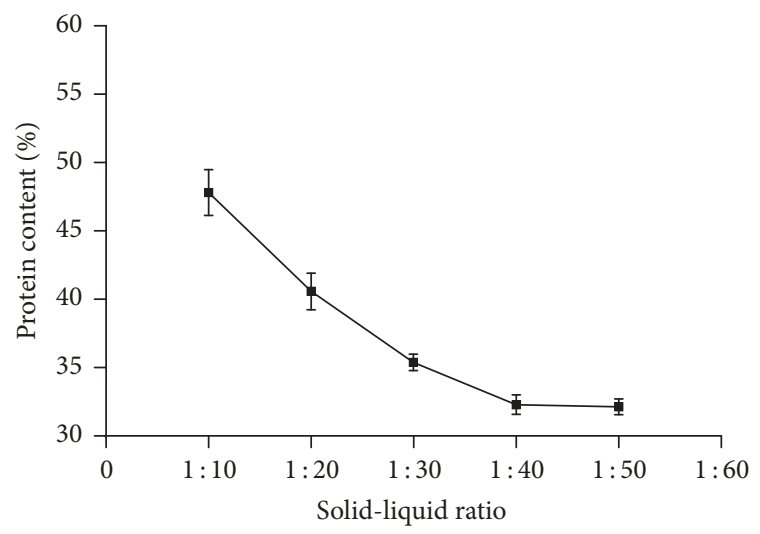

(a)

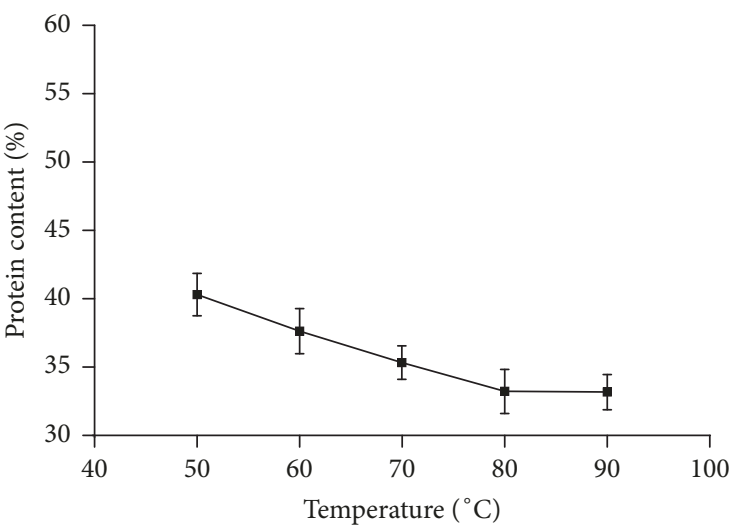

(c)

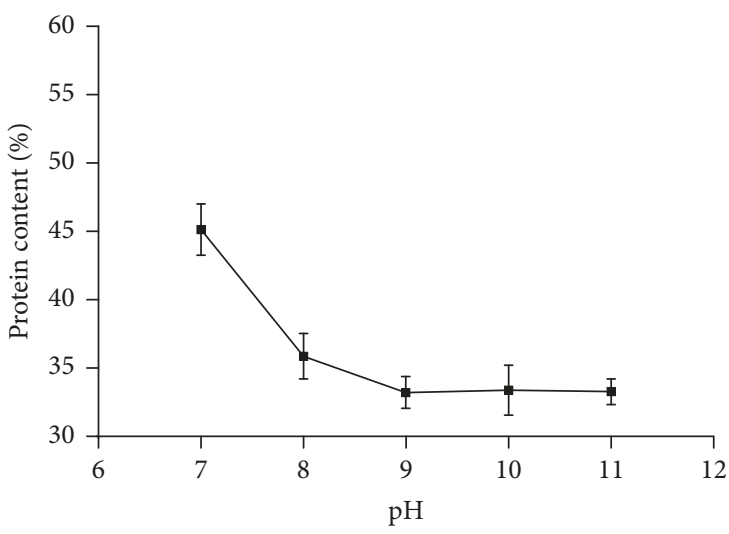

(b)

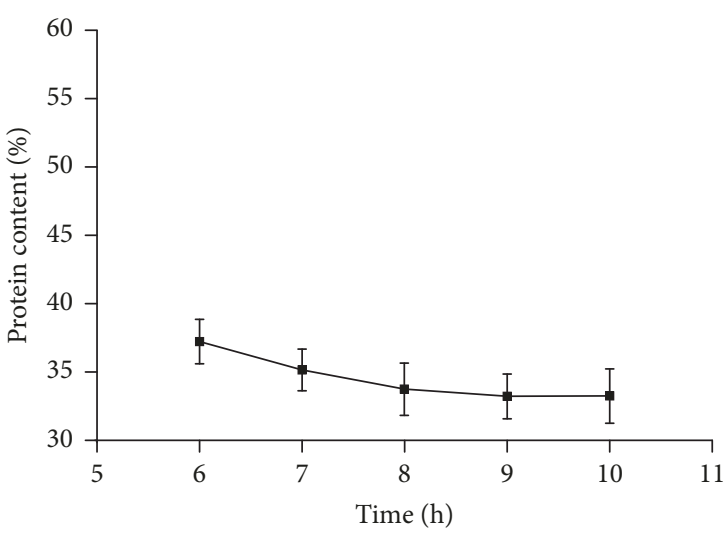

(d)

FiguRE 2: Effect of different ratios of liquid to material (a), $\mathrm{pH}(\mathrm{b})$, temperature (c), and time (d) on protein content.

time. Meanwhile, the effects of different factors on protein content follow the order of $\mathrm{pH}>$ material-to-liquid ratio $>$ water bath temperature $>$ extraction time. In addition, low polysaccharide extraction rate and low protein content were obtained at the material-to-liquid ratios of $1: 30,1: 40$, and $1: 50 ; \mathrm{pH}$ values of $8.0,9.0$, and 10.0 ; temperatures of $70^{\circ} \mathrm{C}, 80^{\circ} \mathrm{C}$, and $90^{\circ} \mathrm{C}$; and extraction times of 8,9 , and $10 \mathrm{~h}$. Therefore, these levels were selected for response surface optimization while designing the response surface scheme.

\subsection{Optimal Process and Verification of Response Surface} Design. Crude polysaccharide extraction was performed according to the 29 groups from the experimental program suggested by the Design-Expert 8.0.6 software. Then, polysaccharide extraction rates and protein contents were determined. The material-to-liquid ratio, $\mathrm{pH}$, temperature, and time were considered as independent variables, whereas the polysaccharide extraction rate and protein content were considered as dependent variables. Multiple linear regression and binary polynomial regression were conducted, and goodness of fit $(r)$ and confidence $(p)$ were used as standard models for judging the result. The results show that the binary polynomial model is better than multiple linear regression, and the model equations are as follows:

$$
Y_{1}=4.91+0.29 X_{1}+0.052 X_{2}+0.067 X_{3}+0.042 X_{4}
$$

$$
\begin{aligned}
& +0.018 X_{1} X_{2}-0.23 X_{1}^{2}-0.012 X_{2}^{2}-0.02 X_{3}^{2} \\
& +0.073 X_{4}^{2}, \quad \text { where }(r=0.9915) .
\end{aligned}
$$

$X_{1}, X_{2}, X_{3}$, and $X_{1}^{2}(p<0.01)$ in these coefficients were highly significant, whereas the others were insignificant.

$$
\begin{gathered}
Y_{2}=33.14-1.02 X_{1}-1.26 X_{2}-0.85 X_{3}-0.41 X_{4} \\
+0.42 X_{3} X_{4}+0.64 X_{1}^{2}+0.49 X_{3}^{2}, \\
\text { where }(r=0.9309) .
\end{gathered}
$$

$X_{1}, X_{2}$, and $X_{3}(p<0.01)$ in these coefficients were highly significant, whereas the others were insignificant.

To observe the interaction between various factors intuitively, we used the Response-Expert ${ }^{\circledR}$ 8.0.6 software continuously for response surface analysis, and a 3D response surface map was produced on the basis of the results of the binary polynomial model fitting (Figure 3 ). The optimal extraction process predicted by the software involved the following conditions: material-to-liquid ratio $=1: 50, \mathrm{pH}=10.25$, water bath temperature $=89.24^{\circ} \mathrm{C}$, extraction time $=9.99 \mathrm{~h}$, predicted PSP extraction rate $=5.21 \%$, and protein content $=$ $30.66 \%$. To facilitate the operation, we chose temperature to 

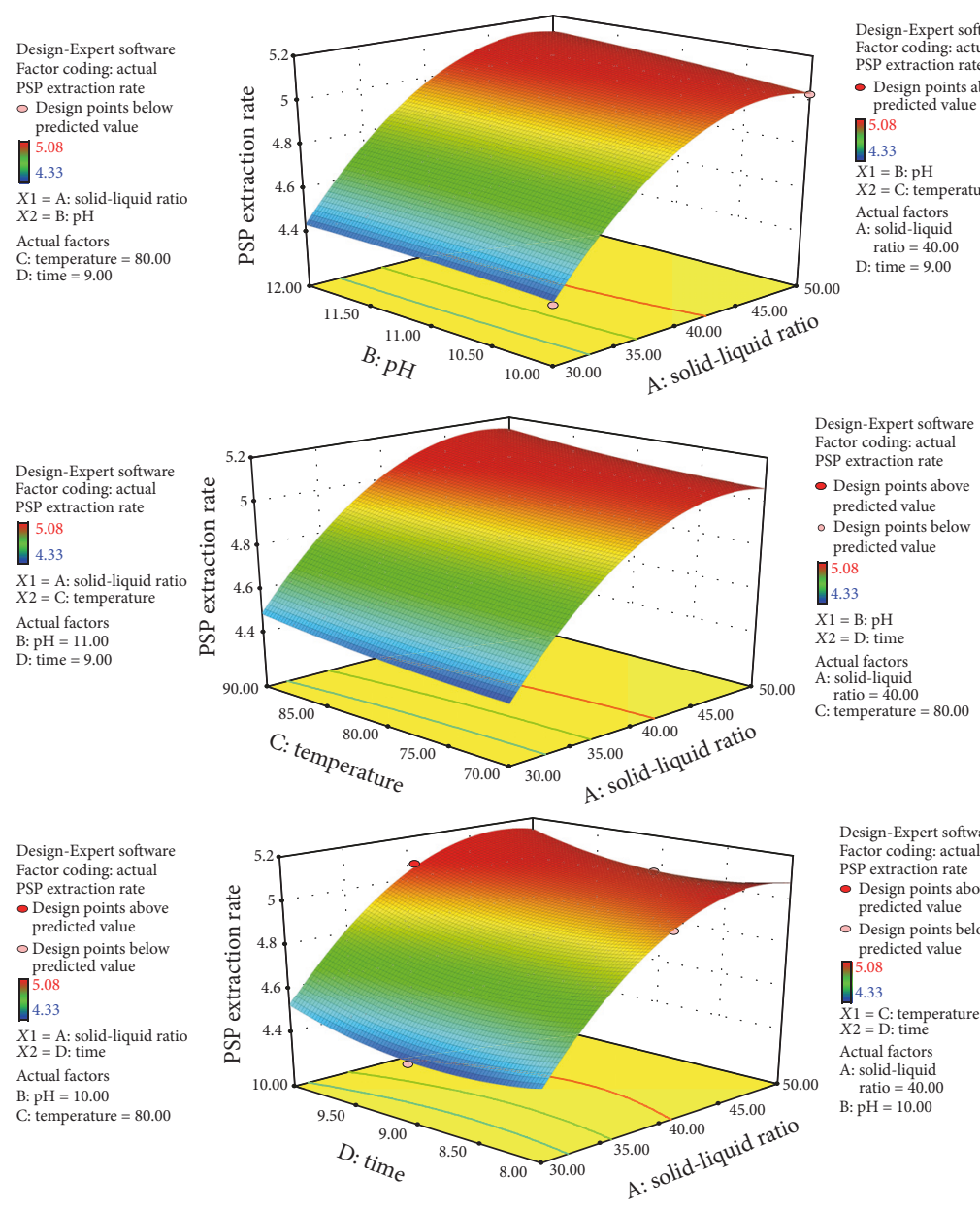
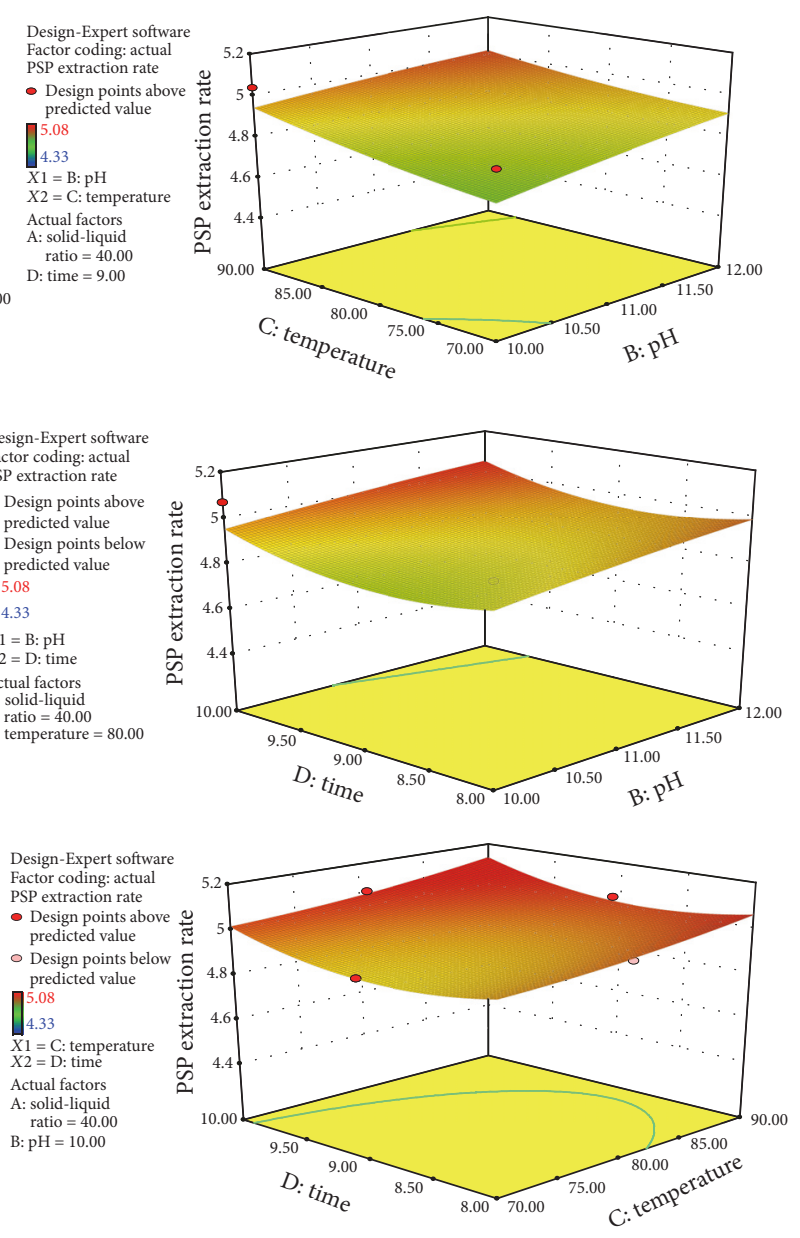

FIGURE 3: 3D response surface scheme of factors and the response values.

TABLE 3: Verification test of the optimized extraction process by RSD $(n=3)$.

\begin{tabular}{lccc}
\hline Index & Predicted value & Actual value & RSD (\%) \\
\hline $\begin{array}{l}\text { PSP extraction } \\
\text { rate (\%) }\end{array}$ & 5.21 & $5.19 \pm 0.02$ & 0.38 \\
$\begin{array}{l}\text { Protein content } \\
(\%)\end{array}$ & 30.66 & $30.96 \pm 0.09$ & 0.29 \\
\hline
\end{tabular}

be $90^{\circ} \mathrm{C}$ and the extraction time to be $10 \mathrm{~h}$. The other conditions remained unchanged. Three batches of samples were prepared in parallel, and the optimal prescription was verified by measuring the PSP extraction rate and protein content. The results are shown in Table 3. The relative deviations of the PSP extraction rate and protein content were less than $2 \%$. This result revealed that the model can effectively reflect the relationship between the indicators and factors.

5.4. Deproteinization and Decolorization Treatment. The extracted PSP was deproteinized by the enzymatic TCA method. The obtained polysaccharide content was $65.71 \pm$ $0.93 \%$ and the protein content was $10.15 \pm 0.14 \%$. Then, the decolorization was continued, and the polysaccharide and protein contents were obtained as $71.65 \pm 1.12 \%$ and $8.54 \pm$ $0.12 \%$, respectively.

5.5. Polysaccharide Components. The results of the monosaccharide composition of PSP analyzed by High Performance Liquid Chromatography are shown in Table 4.

5.6. Effect of PSP on HaCaT Cell Wound Healing. The scratch width of the PSP experimental group (b) and the positive control group with bFGF (c) presented a clear narrowing trend, whereas the scratch width of the normal control group (a) was not significant (Figure 4). Thus, we conclude that the PSP participated in promoting $\mathrm{HaCaT}$ cell migration and fusion, which was similarly to the growth factor bFGF. Thus, PSP exhibited a good effect on wound healing.

\section{Discussion and Conclusion}

In this study, polysaccharide and protein analysis methods were first established. Then, the optimal polysaccharide extraction method was selected among hot-water extraction, alkali extraction, ultrasound-assisted extraction, and 


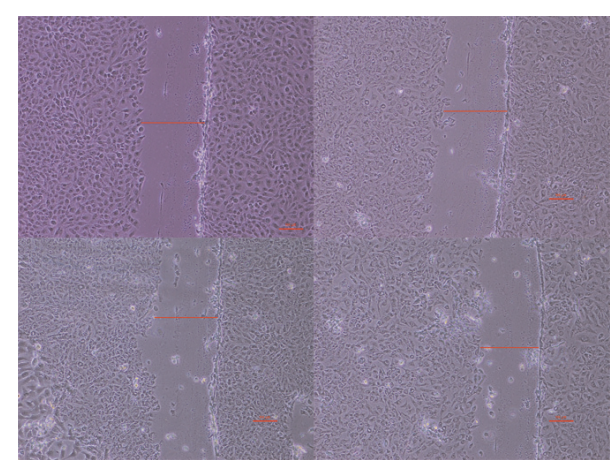

(a)

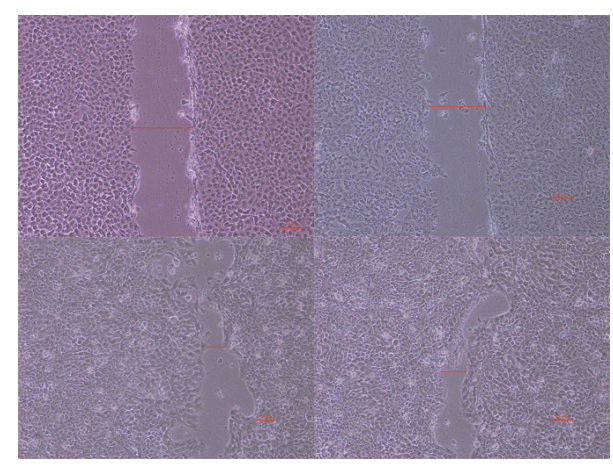

(b)

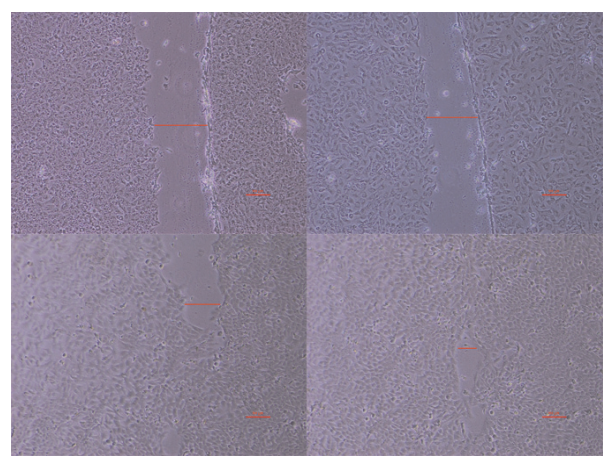

(c)

FIgure 4: Cell scratch test of PSP on HaCaT.

TABLE 4: Monosaccharide composition of crude polysaccharide (\%).

\begin{tabular}{|c|c|c|c|c|c|c|}
\hline Glucose & Rhamnose & Xylose & Galactose & Arabinose & Unknown 1 & Unknown 2 \\
\hline $21.3 \pm 1.4$ & $43.6 \pm 2.7$ & $2.4 \pm 0.6$ & $1.3 \pm 0.2$ & $1.1 \pm 0.1$ & $1.5 \pm 0.3$ & $0.7 \pm 0.4$ \\
\hline
\end{tabular}

the freeze-thaw method. Hot-water extraction does not require special equipment but has lower efficiency than others. Alkali extraction and ultrasound-assisted extraction were developed based on hot-water extraction. Some plant polysaccharides, particularly acidic plant polysaccharides, exhibit high solubility in alkaline solutions. Alkaline solutions are also beneficial for breaking cell walls and releasing polysaccharides to obtain increased extraction rates. However, the alkalinity and temperature must be controlled to prevent polysaccharide hydrolysis. We should pay close attention to alkalinity and temperature control because inappropriate operation may cause polysaccharide hydrolysis. Ultrasound-assisted extraction mainly uses ultrasound to break cells, while the freeze-thaw method involves flash freezing at a low temperature and then gradual melting. The two operations were repeated multiple times to break the cell wall. The principle is as follows: the hydrophobic bond structure is broken after being frozen. Meanwhile, intracellular ice crystals are produced which disrupt the cell wall mechanically. The experimental results showed that the alkali extraction method has a higher efficiency than those of other methods. After univariate analysis, the three most influential factors were used for the analysis of response surface experimental design. In the present experiment, the optimal extraction process was predicted to involve the following conditions: material-to-liquid ratio $=1: 50, \mathrm{pH}=10.25$, water bath temperature $=89.24^{\circ} \mathrm{C}$, extraction time $=9.99 \mathrm{~h}$, predicted PSP extraction rate $=$ $5.21 \%$, and protein content $=30.66 \%$. Then, the extraction process was verified. The crude polysaccharide in bluegreen color was obtained, but it contained high protein. In order to remove the protein, we performed Sevage, enzymatic, enzymatic-Sevage, TCA, and enzymatic hydrolysisTCA methods and compared the deproteinization effects. The enzymatic hydrolysis-TCA method exhibited a better deproteinization effect than others and yielded a protein content of $10.15 \%$. The Sevage method was a protein removal method with a long history. The protein precipitated by denaturation was caused by chloroform, $n$-butanol, and other organic reagents. However, this method which requires repeated processes is unable to denature the proteins tightly bound to polysaccharides and may cause organic solvent residue. The enzymatic protein removal can overcome this problem. However, enzymatic reaction requires increased stringency of the control of conditions. Moreover, the enzyme itself is a kind of protein and may contaminate the sample. In contrast, the TCA method of protein precipitation is more thorough and can remove small amounts of pigment. 
However, this method strictly requires a certain $\mathrm{pH}$ to prevent potential polysaccharide hydrolysis. Considering the advantages and disadvantages of each protein removal method, several techniques are generally combined to improve the protein removal efficiency. When the protein portion was removed, the polysaccharide became light green. Spirulina contains chlorophyll and other pigments. The pigments need to be removed, and oxidative decolorization is the commonly used method. $\mathrm{H}_{2} \mathrm{O}_{2}$ is rapidly decomposed when heated, which generates nascent oxygen and destroys the colored material. The method exerts a decolorizing effect on polysaccharides. Finally, a pale-yellow PSP powder with a polysaccharide content of $71.65 \%$ and a protein content of 8.54 was obtained.

Scratch experiments were performed to compare the skin-damage-repairing effects between the PSP and the growth factor. The effects were found to be almost comparable, suggesting that the PSP exerts good effect on skin repair.

\section{Conflicts of Interest}

The authors confirm that there are no conflicts of interest regarding the publication of this manuscript.

\section{Authors' Contributions}

Bingyue Wang and Qian Liu contributed equally to this work. All authors read and approved the final draft.

\section{Acknowledgments}

This study was financially supported by the Ministry of Education in the New Century Excellent Talents (NECT-120677), the Science and Technology Program of Guangzhou (2014J4500005, 201704030141), the Science Program of the Department of Education of Guangdong (2015KGJHZ012), and the 2017 International Science and Technology Cooperation Project of Guangzhou Economic and Technological Development Zone. This work was supported by the College of Pharmacy, Jinan University, with a thesis write-up grant to Bingyue Wang. The authors are grateful to Yinghong Huang from the Guangzhou Guoyu Pharmaceutical Technology Co., Ltd., and Tiange Cai from the College of Life Sciences, Liaoning University, for their technical assistance.

\section{References}

[1] A. Finamore, M. Palmery, S. Bensehaila, and I. Peluso, "Antioxidant, immunomodulating, and microbial-modulating activities of the sustainable and ecofriendly spirulina," Oxidative Medicine and Cellular Longevity, vol. 2017, Article ID 3247528, 2017.

[2] A. Belay, Y. Ota, K. Miyakawa, and H. Shimamatsu, "Current knowledge on potential health benefits of Spirulina," Journal of Applied Phycology, vol. 5, no. 2, pp. 235-241, 1993.

[3] J. Niu, Z. Pi, H. Yue, Y. Wang, Q. Yu, and S. Liu, "Effect of ginseng polysaccharide on the urinary excretion of type 2 diabetic rats studied by liquid chromatography-mass spectrometry," Journal of Chromatography B, vol. 907, pp. 7-12, 2012.
[4] A. Lovegrove, C. H. Edwards, I. De Noni et al., "Role of polysaccharides in food, digestion, and health," Critical Reviews in Food Science and Nutrition, vol. 57, no. 2, pp. 237-253, 2017.

[5] L. Liu, J. Jia, G. Zeng et al., "Studies on immunoregulatory and anti-tumor activities of a polysaccharide from Salvia miltiorrhiza Bunge," Carbohydrate Polymers, vol. 92, no. 1, pp. 479-483, 2013.

[6] L. Rong, "Extraction, purification and anti-tumor activity of polysaccharide from mycelium of mutant cordyceps militaris," Advanced Chemistry Research, pp. 798-802, 2010.

[7] Z. Li, K. Nie, Z. Wang, and D. Luo, "Quantitative structure activity relationship models for the antioxidant activity of polysaccharides," PLoS ONE, vol. 11, no. 9, Article ID e0163536, 2016.

[8] Y. Guo, L. Cao, Q. Zhao et al., "Preliminary characterizations, antioxidant and hepatoprotective activity of polysaccharide from Cistanche deserticola," International Journal of Biological Macromolecules, vol. 93, pp. 678-685, 2016.

[9] A. D. Bachstetter, J. Jernberg, A. Schlunk et al., "Spirulina promotes stem cell genesis and protects against LPS induced declines in neural stem cell proliferation," PLOS ONE, vol. 5, no. 5, Article ID e10496, 2010.

[10] S. Zhang, S. Nie, D. Huang, J. Huang, Y. Feng, and M. Xie, "A polysaccharide from Ganoderma atrum inhibits tumor growth by induction of apoptosis and activation of immune response in CT26-bearing mice," Journal of Agricultural and Food Chemistry, vol. 62, no. 38, pp. 9296-9304, 2014.

[11] Y.-H. Chen, G.-K. Chang, S.-M. Kuo et al., "Well-tolerated Spirulina extract inhibits influenza virus replication and reduces virus-induced mortality," Scientific Reports, vol. 6, Article ID 24253, 2016.

[12] M.-E. Ngo-Matip, C. A. Pieme, M. Azabji-Kenfack et al., "Effects of Spirulina platensis supplementation on lipid profile in HIV-infected antiretroviral naïve patients in Yaounde-Cameroon: a Randomized Trial Study," Lipids in Health and Disease, vol. 13, article 191, 2014.

[13] N. K. Praveen and K. Chakraborty, "Antioxidant and antiinflammatory potential of the aqueous extract and polysaccharide fraction from brown marine macroalgae Padina $s p$, from Gulf of Mannar of Peninsular India," Coastal Life Medical Journal, pp. 39-49, 2013.

[14] X. M. Li, Y. L. Ma, and X. J. Liu, "Effect of the Lycium barbarum polysaccharides on age-related oxidative stress in aged mice," Journal of Ethnopharmacology, vol. 111, no. 3, pp. 504-511, 2007.

[15] M. Jin, Q. Huang, K. Zhao, and P. Shang, "Biological activities and potential health benefit effects of polysaccharides isolated from Lycium barbarum L," International Journal of Biological Macromolecules, vol. 54, no. 1, pp. 16-23, 2013.

[16] J. Holderness, I. A. Schepetkin, B. Freedman et al., "Polysaccharides isolated from açaí fruit induce innate immune responses," PLoS ONE, vol. 6, no. 2, Article ID e17301, 2011.

[17] X. Dong, L. Fengyin, and L. Ping, "Enhanced extraction of plant polysaccharides," Food and Fermentation Industries, pp. 81-84, 2004.

[18] C. Hong, W. Da-wei, L. Xia, and W. Xiu-juan, "Orthogonalarray-design Optimization of Extraction Technologies of Polysaccharide from Soybeans," in Food Science, pp. 6-10, 2010.

[19] B. Jiang, H. Zhang, C. Liu, Y. Wang, and S. Fan, "Extraction of water-soluble polysaccharide and the antioxidant activity from Ginkgo biloba leaves," Medicinal Chemistry Research, vol. 19, no. 3, pp. 262-270, 2010. 
[20] C. Qu, S. Yu, L. Luo, Y. Zhao, and Y. Huang, "Optimization of ultrasonic extraction of polysaccharides from Ziziphus jujuba Mill, by response surface methodology," Chemistry Central Journal, vol. 7, no. 1, p. 160, 2013.

[21] R. M. Wahlström and A. Suurnäkki, "Enzymatic hydrolysis of lignocellulosic polysaccharides in the presence of ionic liquids," Green Chemistry, vol. 17, no. 2, pp. 694-714, 2015.

[22] C. Zhao, X. Li, J. Miao et al., "The effect of different extraction techniques on property and bioactivity of polysaccharides from Dioscorea hemsleyi," International Journal of Biological Macromolecules, vol. 102, pp. 847-856, 2017.

[23] L. Kui and L. L. Xue, "Study on response surface methodology for alkali extraction of Polysaccharide from thesium," Food Science and Technology, vol. 213, pp. 204-207, 2015. 


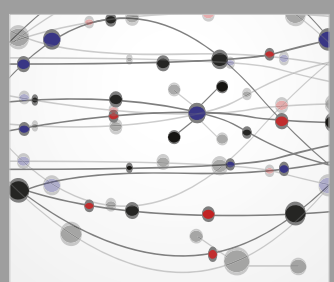

The Scientific World Journal
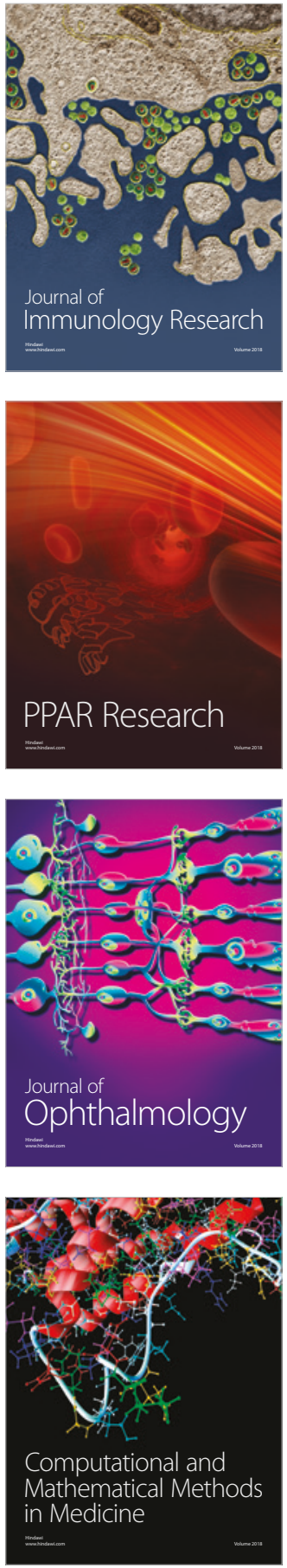

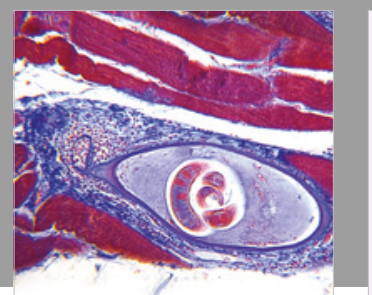

Gastroenterology Research and Practice

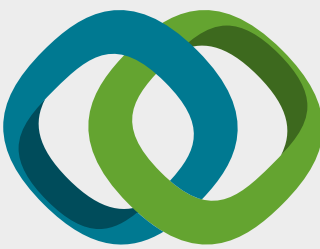

\section{Hindawi}

Submit your manuscripts at

www.hindawi.com
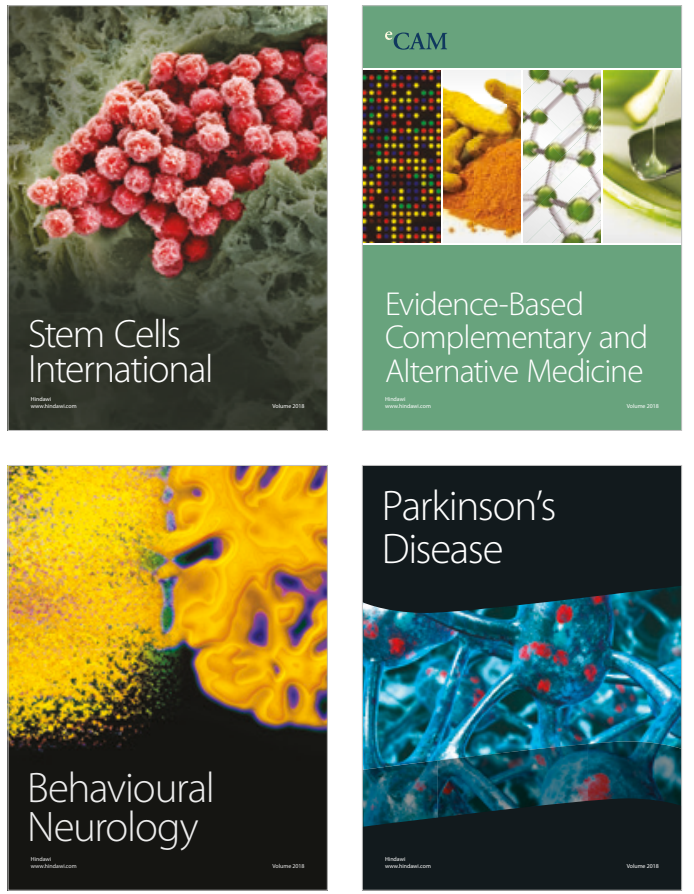

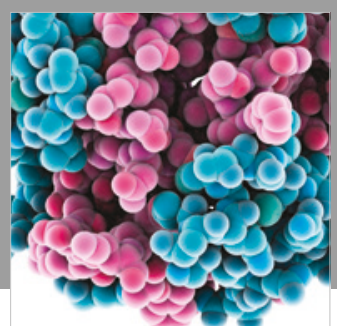

ournal of

Diabetes Research

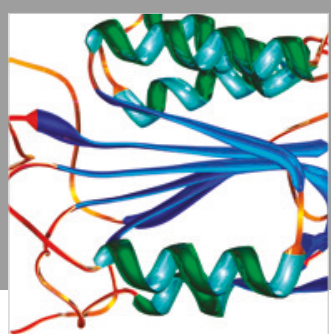

Disease Markers
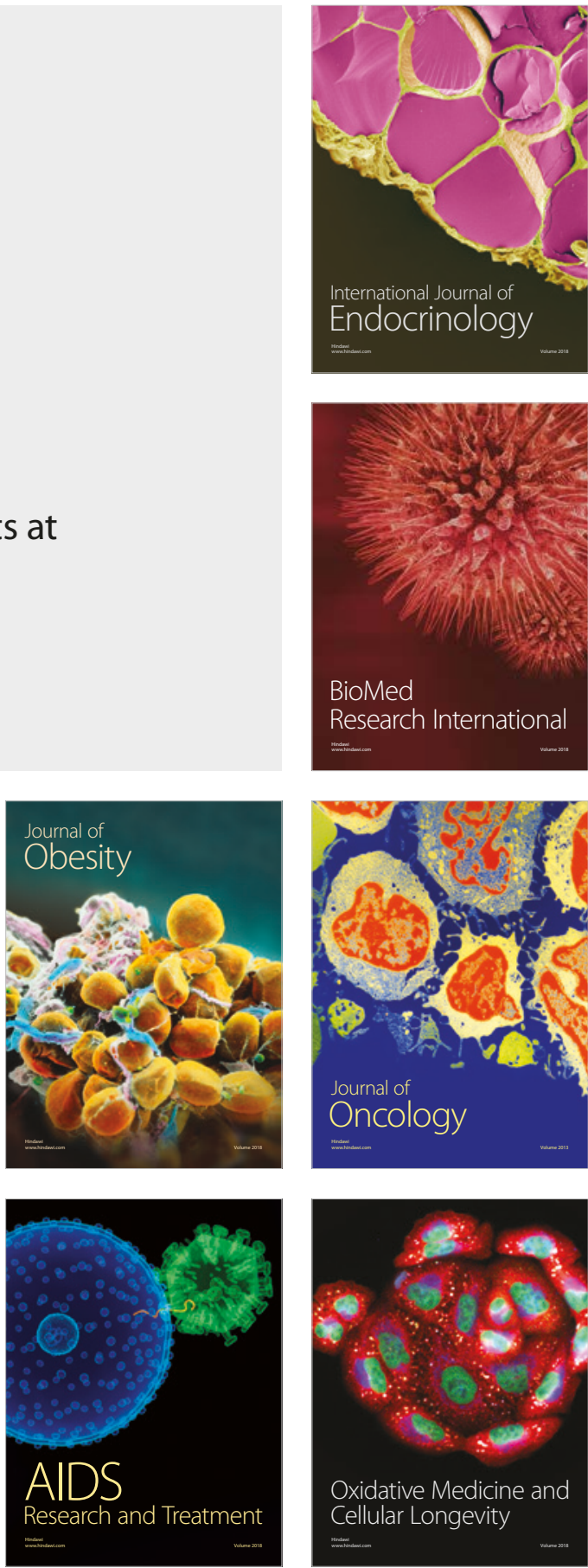